\title{
Sociology of Chronic Pain
}

April 20, 2021

Anna Zajacova, University of Western Ontario

Hanna Grol-Prokopczyk, University at Buffalo, State University of New York

Zachary Zimmer, Mount Saint Vincent University

Total word count: 9,886

Figures: 3

Running head: Sociology of chronic pain 


\section{SOCIOLOGY OF CHRONIC PAIN}

\section{ABSTRACT}

Chronic pain is a common, costly, and consequential health problem. However, despite some important analytic contributions, sociological research on pain has not yet coalesced into a unified subfield. We present three interrelated bodies of evidence, and illustrative new empirical findings using 2010-2018 NHIS data, to argue that pain should have a central role in sociological investigations of health. Specifically, we contend that (1) pain is a sensitive barometer of population health and wellbeing; (2) pain is emblematic of many contested and/or chronic conditions; and (3) pain and pain treatment reflect, and have wide-ranging implications for, public policy. Overall, whether we analyze pain quantitatively or qualitatively-focusing on its distribution in the population, its social causes and consequences, or its subjective meanings for individuals - pain reflects the social conditions, sociopolitical context, and health-related beliefs of a society. Pain is thus an important frontier for future sociological research. 


\section{SOCIOLOGY OF CHRONIC PAIN}

Chronic pain is extremely common, costly, and enormously consequential for health, wellbeing, and productive functioning. It is also, as this article argues in detail, intricately shaped by and reflective of social factors, from the most micro- to the most macro-level. Nonetheless, while chronic pain (often abbreviated below as "pain" for parsimony) has been studied extensively in the biomedical and psychological sciences, sociological research on pain-despite important analytic contributions-has not yet coalesced into a unified subfield. We posit that pain should have a central role in sociological investigations of health, that medical sociology needs to contribute to interdisciplinary scholarship on chronic pain, and that examining pain will enrich both the theoretical frameworks and empirical knowledge base within medical sociology.

Our arguments unfold in six sections. Parts 1 and 2 motivate the sociological study of chronic pain and present brief background on, definitions of, and theories of pain. Parts 3-5 present our core arguments in support of increased sociological attention to pain: that chronic pain is a holistic, sensitive measure of health and wellbeing; that it is emblematic of contemporary contested and/or chronic conditions; and that it is a litmus test of public policy, reflecting the political-economic orientations and "health" of a society and its healthcare system. Part 6 suggests directions for future research. Due to word constraints, many valuable sources could not be cited. However, throughout the article, we highlight scholarly contributions from sociology (including our own new estimates of pain's prevalence, correlates, and association with mortality among US adults); we also draw on interdisciplinary scholarship from biomedical, clinical, psychological, and other disciplines.

\section{PART 1. MEDICAL SOCIOLOGY AND CHRONIC PAIN}

Sociologists have produced an innovative but relatively modest body of research on chronic pain, including early examinations of ethnic and gender differences in pain experiences and expression (Bendelow, 1993; Zola, 1966). Important more recent developments include qualitative examinations of the experiences of women with painful conditions such as fibromyalgia and migraine (Barker, 2005; Kempner, 2014; Pryma, 2017), as well as studies published in JHSB that linked early life course disadvantage to adult pain (Goosby, 2013) and analyzed pain management disparities at safety-net hospitals (Rubin et al., 2018).

Nonetheless - and despite previous explicit calls for a "sociology of pain" (Bendelow \& Williams, 1995)_our field has given short shrift to the topic. Web of Science lists over 166,000 articles, published 2000-2020, with "pain" in their title_-but only 140 are classified under sociology, and many of those use the word figuratively.

Sociological research on pain is, however, imperative. Social conditions shape the causes of chronic pain, its consequences, and even the very experience of pain. Micro-, meso-, and macro-level conditions affect risk factors for pain-inducing conditions or injuries and the likelihood of pain becoming chronic; they shape pain's psychological, social, and financial consequences; they influence how pain patients are treated by the health care and social 
welfare systems and society at large; and, most intimately, they shape intrapersonal perceptions and understandings of pain. While chronic pain is subjective and personal, sociologists are best positioned to illuminate the role of social issues-economic insecurity, discrimination, violence, etc.-in the ostensibly personal pain "troubles" (Mills, 1959). Applying a sociological lens to the study of pain thus expands the range of "independent variables" and moderators in the (literal or metaphorical) "regression equations" to include previously understudied demographic, socioeconomic, and public-policy factors. Moreover, pain is itself an "independent variable." Chronic pain impacts individual and societal outcomes, including population-level health and mortality patterns; macro-level policies including disability benefits; and our orientation toward the opioid epidemic from medical, public health, and criminal-justice lenses.

Sociologists are arguably at a watershed moment for the sociological study of pain. Last year, the World Health Organization (WHO) released the $11^{\text {th }}$ International Classification of Disease (ICD-11), which for the first time classifies chronic pain as a disease (WHO, 2019). This may unleash a flood of biomedical research on the "new" condition-research that would be strengthened by sociological insight. Prominent econometricians have begun analyzing chronic pain (Case \& Deaton, 2020); we can complement their work from a sociological perspective. The hardships of the COVID-19 pandemic may exacerbate pain worldwide, given the tight links between social conditions and pain. And finally, the opioid epidemic-with inherent, if fraught, ties to pain-continues to rage in the US and elsewhere; intense interdisciplinary effort is needed to guide policies to conquer it.

\section{PART 2: CHRONIC PAIN - SELECT BACKGROUND CONCEPTS IN BRIEF}

\subsection{Defining pain}

Defining pain is no easy task. The pioneering pain scholar McCaffery defined pain as "whatever the experiencing person says it is, existing whenever and wherever the person says it does" (Boddice, 2017). The International Association of the Study of Pain (IASP) formulation, which is effectively the official definition in biomedicine, describes pain as "an unpleasant sensory and emotional experience associated with, or resembling that associated with, actual or potential tissue damage" (Raja et al., 2020). Various definitions, however, share the emphasis on the subjective components of pain over the role of underlying physical damage.

\subsection{Acute versus chronic pain: adaptive versus maladaptive}

Acute and chronic pain are often distinguished based on duration, as less versus more than three months. These two classes of pain, however, are profoundly different phenomena (Basbaum et al., 2009).

Acute pain is a life-saving neural alarm system, which alerts us to noxious stimuli --injury or inflammation-- such as a broken bone or appendicitis. It is necessary for survival. Chronic pain, in contrast, persists well past expected healing time, or even emerges without any evident injury to the tissues. It is increasingly understood as a maladaptive source of suffering and disability, 
often decoupled from initial physical damage -if there was any-- and caused or exacerbated by abnormal functioning of the nervous system (Woolf, 2004). The distinction between acute and chronic pain is evident in brain imaging studies where the two activate different areas in the brain (Reckziegel et al., 2019). Chronic pain, moreover, causes large-scale anatomical and metabolic changes in the brain, especially in emotion-related brain circuitry (Hashmi et al., 2013).

The acute-chronic distinction is central also to the question of whether pain is just a symptom of one of countless diagnoses or a condition in its own right (or whether it can be both). If pain is largely a symptom of a disease or injury, as is acute pain, then research should focus on the underlying disease. For much of the $20^{\text {th }}$ century, in fact, medicine viewed pain largely as a symptom, causing a vicious circle: pain was viewed as secondary, research was limited, and our understanding of pain lagged (Raffaeli \& Arnaudo, 2017). Fortunately, with gradual appreciation of the distinct nature of chronic pain, medical research now views at least some pain as an independent condition (Siddall, 2013), a notion supported by chronic pain's addition to the ICD-11 (WHO, 2019). The complex classifications and typologies of pain notwithstanding, sociological research is justified in examining chronic pain as an entity in itself, based on its common social causes, consequences, and contexts, as discussed in later sections.

\subsection{Historical and current pain frameworks}

Scholars have theorized pain since antiquity. Early understanding of chronic pain was holistic and metaphysical or spiritual. In medieval Europe dominated by the Christian worldview, pain was accepted as punishment for sins ("pain," "penalty," and "punishment" share the same Latin root), and even sought as evidence of one's piety (Boddice, 2017). In the mid-17 $7^{\text {th }}$ century, Descartes overthrew millennia-old notions and defined pain as a sensation transmitted directly from a point of injury in the body to the brain. This mechanistic view underpinned Western understanding of pain for the next three centuries. It is evident across all early modern theories of pain developed in the $19^{\text {th }}$ and early $20^{\text {th }}$ centuries, including the influential Specificity Theory, which posited, incorrectly, that a dedicated "pain center" in the brain processes stimuli from specific pain receptors (Moayedi \& Davis, 2013).

By the mid- $20^{\text {th }}$ century, this Cartesian understanding was increasingly recognized as inadequate and was finally superseded by the paradigm-shifting Gate Control Theory (Melzack \& Wall, 1965). The theory postulates that structures in the spinal cord act as a 'gate' that can modulate the ascending pain signals while the brain itself has pain-regulating mechanisms that shape the pain sensation. Further elaborations, such as Neuromatrix Theory (Melzack, 1999) gave the brain an even more central role in the production of the pain experience. The emphasis of the role of the central nervous system as not only in passively perceiving but actually generating pain paved the way for the current biopsychosocial model.

The biopsychosocial model has dominated pain research for four decades (Turk et al., 2011a). This model expands Melzack's view of the central role of the brain and recognizes a broad array 
of "psychosocial" mechanisms affecting chronic pain. Unfortunately, the expansion into psychosocial factors stopped in the department of psychology. Thus the "social" part of the model's name is better understood as "social psychological" factors: interpersonal, affective (emotional), and cognitive inputs including social support, beliefs, attitudes, self-efficacy, cognition, coping, and affects including distress, depression, and anxiety (Gatchel et al., 2007). Even if "social forces" or "social determinants" are specifically mentioned in this literature, they still refer largely to interpersonal social-psychological factors (Craig \& Fashler, 2013).

Thus, the currently predominant model of pain neglects the role of structural inequalities that shape who experiences pain, how they experience it, and how others view their pain, let alone upstream, fundamental driving factors such as public policy, the medical-industrial complex including pharmaceutical and health insurance industries, and socio-political context that underlies all these factors and their interrelationships (Montez, 2020; Wailoo, 2014). To ignore these upstream determinants is to have an incomplete understanding of pain, just as Link and Phelan have warned regarding overall health (Phelan, Link, \& Tehranifar, 2010). Medical sociology can and must rebalance the lopsided biomedically-focused pain models with our expertise on the social context and appreciation of its profound effect on pain if we are to understand the profound impact of pain on society and the way in which the structure of societies influence pain.'

\section{PART 3. PAIN AS A BAROMETER OF POPULATION HEALTH}

Chronic pain is a sensitive barometer of population health and wellbeing. In this section, we review characteristics that jointly support this claim. We show that pain has enormous health and social consequences; is universal, that is, relevant to all and affecting many; at the same time is unequally distributed in society, reflecting existing structural inequities; and is inextricably linked with multiple dimensions of physical and mental health and wellbeing.

Population-health scholarship often relies on holistic indicators of health, such as self-rated health. Pain, as a broad construct with a multitude of possible causes and correlates, can serve a similar role, but with the added strength of direct clinical and policy implications. Another strength of chronic pain for population-health research is its inherently subjective nature: its "gold standard" measurement is a person's own assessment (Boddice, 2017), unlike for many other health measures (i.e., chronic conditions) for which medical records are considered the gold standard. Additionally, major population-health surveys collect information about pain, sometimes longitudinally or in repeat cross-section, typically in one of two forms. Global pain questions (e.g., in the Health and Retirement Survey), ask "Are you often troubled with pain?" A positive answer can be followed with questions about pain intensity and/or interference with daily activities. A site-specific approach (as in the National Health Interview Survey), asks a series of questions with respect to particular body sites such as low back, neck, or joints. 


\subsection{The far-reaching consequences of pain}

Chronic pain exacts a heavy price from affected individuals, their families, and society at large. For individuals, pain is a major "biographical disruption" (Bury, 1982) that can destroy "the self" (Charmaz, 1983) and derail all aspects of life trajectory. Pain interferes with work, daily activities, and is the leading cause of disability (Zimmer \& Rubin, 2020), which can cascade to subsequent social, occupational, and economic problems. Pain disrupts sleep, increases fatigue, compromises cognitive function (Turk et al., 2016) and doubles the risk of suicide (Racine, 2018).

Beyond the individual, pain affects the entire family, workplace, and other social structures where the sufferer is embedded. Pain reduces productivity and increases absenteeism, which can have repercussions for others in the workplace (Dueñas et al., 2016). Pain impedes the ability to carry out social roles, such as those of a parent or a partner, leading to feelings of loss, stress, anger, resentment, and helplessness across the family unit (Strunin \& Boden, 2004). Family and friends struggle watching their loved one in pain but also may feel burdened by the needed caregiving (Dueñas et al., 2016).

At the national level, such consequences are multiplied by the 100 million Americans who are estimated to be affected by chronic pain (Institute of Medicine, 2011). The prevalence estimates range from about $10 \%$ with high-impact pain to upwards of $40 \%$ using broader definitions of pain (Dahlhamer et al., 2018; Zajacova, Zimmer, \& Grol-Prokopczyk, 2021), and costs in the US exceed $\$ 300$ billion annually in lost productivity alone, with an additional $\$ 300$ billion for health care, dwarfing the costs of all other leading causes of morbidity and mortality (Gaskin \& Richard, 2012).

Moreover, pain prevalence is increasing steeply across all studied population groups in the US (Zajacova et al., 2021; Zimmer \& Zajacova, 2020) and other countries (Rice, Smith, \& Blyth, 2016; Zimmer, Zajacova, \& Grol-Prokopczyk, 2020). Experts expect chronic pain to increase further in the aftermath of the COVID-19 pandemic (Clauw et al., 2020), due in small part to postviral pain syndromes, but primarily due to economic collapse, social stressors, anxiety, social isolation, reduced physical activity, and unavailable medical care. The combination of pain's high prevalence and continued increase lends urgency to medical sociologists' task to better understanding and help reverse these distressing trends.

\subsection{Pain disparities}

While pain affects people from all walks of life, its prevalence differs markedly across population groups. By far the most widely studied pain disparities, especially in biomedical research, are gender/sex differences. However, even in population-health scholarship, gender differences have been studied extensively, and findings are consistent: nearly universally, women report higher prevalence of pain than men (Jay et al., 2019; Kennedy et al., 2014). 
Much less research exists on other disparities. Lower socioeconomic status (SES), whether operationalized with education, income, or other measures, is generally found correlated with higher pain prevalence (Dahlhamer et al., 2018; Goosby, 2013; Janevic et al., 2017). Findings for racial and ethnic disparities are less consistent. Some research shows that Black and Hispanic respondents report less pain than their White counterparts (Kennedy et al., 2014; Zajacova et al., 2020) but other studies-especially if taking into account pain intensity and respondents' SES—show comparable (Janevic et al., 2017) or higher (Grol-Prokopczyk, 2017) prevalence in non-White adults.

Figure 1 illustrates disparities in severe pain in a representative sample of US adults (Online Appendix explains methods and approach). About $10 \%$ of men and $13 \%$ of women report severe pain. While $11 \%$ of non-Hispanic White and Hispanic Americans report severe pain, the proportion is over $15 \%$ for Black and only $8 \%$ of "Other" respondents. These demographic disparities are important and sizeable, yet socioeconomic gradients are staggering in comparison. Fewer than $7 \%$ of college graduates report severe pain, while among Americans without a high school diploma, the percentage is nearly triple: $19 \%$. And similarly, by family income, only $6 \%$ of the highest-income group, but $19 \%$ of the lowest-income group, report severe pain. An interesting exception to the monotonic SES gradient pertains to adults with some higher education, who have slightly more severe pain than adults with a high school diploma, an anomaly examined elsewhere (Zajacova et al., 2020). Our illustration thus shows that the amply-studied gender differences pale in comparison with the larger race and massive socioeconomic disparities. The results provide justification for social science research on this surprisingly understudied area.

\subsection{Pain and other health dimensions}

Pain is closely connected with effectively all dimensions of physical and mental health. Figure 2 (see Online Appendix for analytic details) illustrates these strong correlations. Pain is tightly coupled with self-rated health; dimensions of mental health such as depression, fatigue, and anxiety; functional limitations, as well as arthritis. Such correlations at the population level were described previously (Nahin, 2015; Rubin \& Zimmer, 2015). Pain, like other chronic conditions, tends toward comorbidity: experiencing pain goes hand in hand with other conditions (Patel et al., 2013), especially those that are pain-related, such as arthritis, but also those with little evident pain component, such as hypertension (Zajacova et al., 2021). In this sense, pain is both a unique condition in its own right, as well as a cause and an effect of other conditions.

Pain is particularly intimately linked with disablement - they often co-occur (Zimmer \& Rubin, 2020). Respondents who were "often troubled with pain" had six times the odds of functional limitations and eight times the odds of ambulatory difficulty, compared with respondents without pain (Smith et al., 2018). Yet despite the inextricable connection, pain is given short shrift in widely-used models of health disability (Verbrugge \& Jette, 1994; World Health Organization, 2013). The seminal Verbrugge and Jette formulation of the Disablement Process (1994), for instance, mentions pain only parenthetically. This is quite puzzling—after all, people limit 
activities most often because they experience pain (Zimmer \& Rubin, 2020). Thus, pain -its presence and severity-- should be a central component of any disablement framework.

The strong links between pain and mental health have been documented extensively, especially for depression and anxiety (Goosby, 2013; Gureje et al., 2008), but also anger (Greenwood et al., 2003), and suicidal ideation or suicide (Racine, 2018). Even relative to a host of social and medical correlates, psychological distress is a highly salient predictor of pain levels and trends (Zajacova et al., 2021). The links are complex and certainly bidirectional and reciprocal, so that distressed mental states exacerbate pain, and the presence of pain exacerbates distress (Viana et al., 2018). Mounting evidence reveals that social pain, such as social exclusion or discrimination, shares neural mechanisms with those processing physical pain, particularly its affective component (Eisenberger, 2015). Thus, factors that increase exposure or vulnerability to social pain may also increase exposure and vulnerability to physical pain and vice versa.

Finally, pain, particularly severe pain, likely also predicts mortality. Figure 3 shows that moderate and especially severe pain are associated with substantially lower survival compared with no or mild pain (see Online Appendix for more information), even after controlling for a host of sociodemographic variables in a sample of US adults. This illustrative finding corroborates the rapidly evolving literature on pain and mortality. Seven years ago, a systematic review on pain and mortality found only 10 papers suitable for inclusion; the authors concluded that pain was associated with only modestly higher mortality (Smith et al., 2014). Just three years later, the prominent epidemiologist of pain Gary MacFarlane declared that the "evidence is clear" that pain, at least severe/widespread pain, is associated with excess mortality (2017). Explanations for the association are not well understood, but potential mechanisms include pain medication (Cleveland, Nelson, \& Callahan, 2019) and pain's potential to increase allostatic load, suppress the immune system, and impair tissue repair (Gatchel et al., 2007).

\section{PART 4. INVISIBLE, CONTESTED, AND INTRACTABLE}

Chronic diseases have been the leading causes of death and disability in the US since the mid20th century. A large number of chronic health problems feature psychiatric or physical symptoms for which no biological explanation can be found: roughly $50 \%$ of medical consultations feature such "medically unexplained symptoms" (O'Leary, 2018). While sociological focus on pain would be warranted by pain's high prevalence and profound consequences alone, pain's frequent unverifiability, inexplicability, and long duration also make it a telling test case for how individuals and institutions contend with contested, intractable conditions in general. These disease characteristics strongly shape illness experiences, patientprovider relations, the invocation of gender, racial, and other stereotypes, and pain treatment and research.

\subsection{Pain's profound invisibility and its consequences}

Qualitative social scientists have shown a consistent fascination with what Baszanger (1992) calls the "fragile factuality" of pain, i.e., its invisibility and unverifiability (Barker, 2005; Jackson, 
2011; and many others). While some authors refer to conditions such as diabetes and lupus as "invisible" since they cannot be seen directly (Joachim \& Acorn, 2000), often these conditions can be diagnosed and verified by medical professionals through the tools of biomedicine. Pain, however, cannot achieve such "mediated visibility" but retains a "profound invisibility" (GrolProkopczyk, 2013): no instrument, blood draw, or biopsy can quantify it. Scientists have long pursued objective measures of pain, such as through brain imaging, but as a recent $\mathrm{NIH}$ sponsored consensus statement attests, the candidate measures are only "potential pain biomarkers," and remain infrequent in clinical trials or practice (Davis et al., 2020, emphasis added).

Furthermore, while some health conditions can be verified and measured by quantifying their underlying cause (e.g., hemophilia can be diagnosed and graded via the quantity of clotting factors in the blood), pain remains elusive here as well, since the correlation between observed physical pathologies and experienced pain is surprisingly weak. One can experience great pain with no perceptible cause, as in fibromyalgia (Barker, 2005), or no pain in the presence of documented pathology, such as degenerative spinal discs (Emch \& Modic, 2011). Lacking objective measures, clinicians and researchers must rely primarily on patients' subjective selfreports to assess pain.

Unsurprisingly, self-reports are a problematic basis for pain measurement and verification. As trenchantly expressed by Scarry, "[t]o have great pain is to have certainty; to hear that another person has pain is to have doubt" (1985:7). Doubt surrounding claims of pain is, indeed, rampant. Studies report with remarkable consistency that pain patients experience skepticism and accusations of malingering or hypochondria from family, friends, employers, health care providers, etc. (Crowe et al., 2017; Glenton, 2003; Jackson, 2011; Pryma, 2017). Pain patients report "feeling disrespected and distrusted, suspected of drug-seeking, and having their symptoms dismissed as trivial and/or not warranting medical care" (Upshur, Bacigalupe, \& Luckmann, 2010:1791). These feelings appear to be justified: doctors often do doubt the credibility of their pain patients' complaints (e.g., Matthias et al., 2010), and conditions featuring pain are all-too-well represented among "contested illnesses" (Barker, 2011). Many people with pain report that invalidation and stigmatization damage their social lives and sense of identity. Such experiences contribute to "biographical disruption" (Bury 1982), and have led to theories of pain as "an assault on the self" (Smith \& Osborn, 2007) or "a threat to the social self" (Karos et al., 2018).

Pain's unverifiability and poorly understood etiology give health care providers much leeway in deciding how much pain a patient is "really" experiencing. The pain patient becomes a blank slate onto which others project stereotypes of exaggeration or stoicism, physical or psychological weakness, drug-seeking behavior, etc.-stereotypes strongly related to gender, race/ethnicity, and class. Kempner (2016:1048) traces medical and literary depictions of migraine sufferers as weak, neurotic women back to at least the $18^{\text {th }}$ century, and notions of "stoic men" and "sensitive" or "hysterical" women remain pervasive in $21^{\text {st }}$ century medicine 
(Samulowitz et al., 2018). These notions, importantly, shape treatment: men with pain are more likely to be offered surgery or opioids while women are substantially more likely to be prescribed psychotropic medications for depression and anxiety (Thernstrom, 2010). Similarly, false beliefs about Blacks' lesser pain sensitivity vis-à-vis Whites, combined with racialized stereotypes of drug addiction and diversion, shape contemporary pain treatment (Hoffman et al., 2016). Minorities, especially men, are less likely to be prescribed analgesics than Whites, and if they are prescribed opioids, are more likely to be given urine tests or substance abuse assessments (Hausmann et al., 2013). The limited evidence on social class disparities indicates that class interacts with sex and race in shaping perceptions and treatment of pain patients (Rubin et al., 2018). While health conditions need not be invisible and unverifiable to be subject to gender, racial/ethnic, or other stereotypes, these characteristics make resistance to stereotypes appreciably more difficult.

\subsection{Pain's therapeutic intractability and its consequences}

Pain often lasts or recurs for years. Over $70 \%$ of people with back pain, for instance, continue to experience symptoms four years later (Smith et al., 2004), and 85\% of people with widespread pain (in three or more bodily locations) still experience it 12 years later (Andersson, 2004). Pain intensity may wax and wane over the course of weeks, days, or hours, and these patterns may shape pain's psychological and social consequences. For example, back pain sufferers report that having "good days," during which they can perform normal tasks, harms their credibility on bad days when pain disables them (Glenton, 2003).

Pain's frequent long duration reflects the limits of the modern medical armamentarium. Review articles on chronic pain treatment are, by their own admission, "sobering," concluding that "present treatment options result in modest improvements at best" for pain itself, and "minimum improvements in physical and emotional functioning" (Turk, Wilson, \& Cahana,

2011b:2226,2232). Baszanger's (1992) ethnography of French pain clinics described a schism between doctors who expected to cure chronic pain and those who aspired only to manage it. At present, however, the vast majority of pain specialists fall into the latter, more pessimistic camp, likening pain to lifelong, incurable conditions such as diabetes, which can be managed but not cured (Grol-Prokopczyk, 2013).

Pain's therapeutic intractability is a problem for both pain patients and those who treat them. The prominent late $19^{\text {th }}$ century physician Sir William Osler quipped, "When I see [pain patients] coming in the front door, I leave by the back door"; over a century later, clinicians' still view pain treatment as "frustrating and challenging" (Graf, 2010:1976). For medical researchers, the difficulty of treating pain itself (i.e., pain intensity) has led many to re-focus their work on a varied set of putatively more treatable outcomes, such as pain-related disability. As one researcher explained, "Pain is really a secondary outcome of interest, since there is no guarantee that pain can be cured or reduced, but we know we can help people improve functionally despite the pain" (Grol-Prokopczyk, 2013). This shift from pain intensity to other outcomes may make pain a more "do-able" problem (Fujimura, 1996) for clinicians and 
researchers - but it may also put them at odds with patients, who frequently hold out hope for curing the pain itself. Pain doctors describe how substantial "expectations management" is required to "talk people out of the 'cure' belief"-if they succeed in doing so at all (GrolProkopczyk, 2013).

Together, pain's invisibility and intractability, clinicians' skepticism, the limited efficacy of existing treatments, and the tension between cure and management as treatment goals make patientprovider interactions deeply fraught. Physicians' role as gatekeepers controlling access to disability benefits and high-risk medications, including opioids, creates further tensions (Pryma, 2017; Rubin et al., 2018). Pain patients are often highly disappointed with the quality of their care (Hadi et al., 2017), and "[r]elations between pain patients and health care deliverers" have been deemed "the worst in medicine" (Jackson, 2011:348).

Scholars note that Parsons's formulation of the "sick role"-that is, the responsibilities, exemptions, and benefits that society affords to a sick person-is based on an acute disease model, in which sickness is verifiable, curable via medical experts' advice or intervention, and of limited duration (Crossley, 1998; Glenton, 2003). It appears that alternative models to incorporate the chronically ill-especially those with unverifiable conditions-are lacking. Thus, like square pegs in a round hole, chronic pain patients attempt to emulate Parsons's idealtypical patient, seeking out concrete physical diagnoses and effective biomedical treatmentsand experiencing delegitimation and stigma when the diagnoses and/or treatments cannot be found (Glenton, 2003).

\subsection{Commonalities and variability in the pain experience}

Certain themes in research on the chronic pain experience recur so frequently that they appear nearly universal. A review of diverse chronic pain conditions reports several consistent "metathemes" related to topics mentioned above, including "invisible but real" and "disrupted sense of self" (Crowe et al., 2017). At the same time, sociological research highlights variability in pain experiences, as shaped by characteristics including gender and race. Studies document how gender stereotypes and structural inequalities negatively affect women's experiences of chronic pain conditions (e.g., Barker, 2005; Kempner, 2014). Pryma (2017) finds that Black and white US women with fibromyalgia frame their claims of pain differently, due to highly racialized discourses regarding morality, worthiness, and disability. Scholarship on sickle-cell anemia, which in the US predominantly afflicts Black Americans, also underscores how the pain experience is inextricably grounded in specific historical, political, and cultural contexts (e.g., Rouse, 2009).

Future research could enrich our understanding of pain by exploring heterogeneity not only across sociodemographic groups but also across disease characteristics and institutional contexts. How are pain experiences shaped by pain severity/interference, duration, or stage of the "disease course" (Yang \& Grol-Prokopczyk, 2020)? How are they shaped by national- or 
state-level health insurance or disability benefit programs? The salience of policy contexts is addressed in the next section.

\section{PART 5. PAIN, POLICY, AND OPIOIDS}

Chronic pain presents a paradox: it is a deeply personal subjective experience, yet it is also inextricably interwoven with politics and policy up to national or even global levels. Some argue that questions of whose pain is legitimate and what relief they deserve lie at the core of much political discourse and decision-making about the US welfare state since the mid-20 ${ }^{\text {th }}$ century (Wailoo, 2014). Similar questions motivate global institutional initiatives, such as the WHO's and IASP's advocacy of pain management as a human right (Brennan, Carr, \& Cousins, 2007). Policies particularly relevant to pain include the social welfare systems that shape overall wellbeing and socioeconomic contexts; regulation of the development, marketing, and prescribing of analgesic pharmaceuticals; health insurance coverage (or non-coverage) of specific pain treatments; and disability insurance policies.

For example, the Social Security Disability Insurance (SSDI) is critical for many with pain severe enough to interfere with work. Yet the SSDI requires a proof of underlying "medically determinable impairment," which must be documented by "clinical or laboratory diagnostic techniques" such as X-rays or MRIs (Social Security Administration, 2017). Given the low correlation between observable physical damage and experienced pain, this requirement is problematic (Case \& Deaton, 2020; Pryma, 2017) and may lead to a vicious downward spiral of pain, economic loss, and distress for many Americans.

Complex policy influences are also evident in the opioid epidemic, which, over the last 20 years, killed almost half a million Americans (CDC, 2020). On one hand, opioids are a lifesaver (metaphorically, but also literally) to some pain patients (Thernstrom, 2010). On the other hand, there is astonishingly little evidence of opioids' effectiveness in long-term use (Chou et al., 2015) in contrast to well-documented adverse side effects and outcomes including depression and reduced immune function (Grol-Prokopczyk, 2019). Indeed, opioids may actually worsen chronic pain over time because they increase sensitivity to pain (Green-Fulgham et al., 2019).

Given this fraught portrait, why are opioids the most widely prescribed medication class in the US (Volkow \& McLellan, 2016), and the primary treatment for chronic pain sufferers (Jones et al., 2018)? The answer, again, is grounded in historical political, medical, and pharmaceutical developments. For much of $20^{\text {th }}$ century, medicine had a strong aversion to opioids, buttressed by criminal legislation and an anti-opioid culture; even severe terminal cancer pain was often undertreated.

This changed in the 1980s and 1990s: A misinterpreted 1980 letter to the editor of JAMA incorrectly assuaged doctors' fears of opioid dependence and addiction; hospital-accrediting organizations began promoting aggressive pain treatment to increase patient satisfaction; and changing health care reimbursement models led to widespread closures of interdisciplinary pain clinics, leaving pharmacological treatments as the most feasible option for time-strapped 
providers. Concurrently, pharmaceutical companies developed supposedly addiction-proof analgesics, most notoriously Oxycontin, and, owing to inadequate government oversight, marketed them aggressively and sometimes deceptively to physicians and patients alike (e.g., Jones et al., 2018). Over time, low-income Medicaid enrollees came to disproportionately rely and overdose - on opioids, reflecting Medicaid's coverage of opioids but not many alternative pain treatments (Grol-Prokopczyk, 2019).

These developments occurred in the context of a disintegrating social safety net, mounting economic stresses, and "despair" among many Americans (Case \& Deaton, 2020), increasing their susceptibility to pain and demand for opioids. In recent years, the pendulum swung back toward more restrictions on opioid prescribing (Chiarello, 2015), leaving many patients stranded and struggling to manage their pain.

In sum, policies including welfare state retrenchment, inadequate government regulation of a profit-hungry pharmaceutical industry, and health insurance coverage policies conspired to produce skyrocketing increases in long-term opioid use. More broadly, pain's prevalence, disparities, consequences, and treatments reflect and shape intersecting political-economic forces in medical, commercial, legal, and ethical realms.

\section{PART 6. NEW RESEARCH DIRECTIONS / OPEN QUESTIONS}

As previous sections have shown, social factors at every level of analysis shape who experiences pain, how pain is experienced, and how pain is treated in health care and society. Below, we identify particularly promising and important directions for further investigation, in support of a full-fledged sociology of chronic pain.

\subsection{Causes of pain}

Pain prevalence is increasing in the US and elsewhere, and it is important to understand why. Might it be related to breakdown of the social and economic fabric for all but the most advantaged Americans (Case \& Deaton, 2020)? If so, what mechanisms link this contextual deterioration to pain? What is the role of changing employment patterns, increasing obesity (Stokes et al., 2020), pervasive opioid use, psychological distress, or even changing expectations and thus reporting of pain?

In addition, pain prevalence varies markedly across groups. We must explore the intersections of age, gender, race/ethnicity, and socioeconomic status, as they each have unique and interactive impacts on life trajectories and, correspondingly, on pain. Moving 'upstream' from individual characteristics, why do rural areas (Johannes et al., 2010) and states in the South, West, and Appalachia (Case \& Deaton, 2020) suffer disproportionately high pain burden? Comparison of US states can highlight the role of socio-political contexts (Montez, 2020): how do state government policies, health care systems, or cultural expectations affect the burden of pain in the US? 
Sociology has two unique strengths in answering such questions. First, medical pain specialists, who dominate current pain research, tend to see the most severe and intractable pain cases, and often focus on particular pain diagnoses. Quantitative sociologists, in contrast, rely on representative, general population samples, which provide a more comprehensive and balanced picture of pain's severity, causes, and consequences. Second, unlike biomedical approaches that focus on proximal causes, medical sociologists better grasp sociopolitical structures as upstream "causes of causes" (Galea \& Vaughan, 2018). This broader picture is necessary for a full understanding of pain, and for effective interventions.

\subsection{Consequences of pain}

We need to better understand the far-reaching consequences of pain on individuals, families, and social systems. How does chronic pain influence the economic wellbeing of affected individuals and their families? How do pain sufferers navigate the workplace, especially for the precariously employed? And what is pain's impact on spousal, parental, and caregiving relationships, as well as friendships and other social ties? Beyond these micro and meso-level consequences, what is the sociocultural, economic, and political impact of pain at national and global levels?

Important open questions remain also about the health consequence of pain. Quantitative studies could further explore how and under what circumstances pain influences mortality; the role of pain in the disablement process; and pain's contributions to cognitive aging (Moriarty, McGuire, \& Finn, 2011). Qualitative sociological studies could explore the parallels between pain and other chronic, invisible health conditions, and could help interrogate and suggest alternatives to common models of health problems as verifiable, treatable, and temporary.

\subsection{Institutions, sociopolitical context, and pain}

Sociological scholarship on pain has often explored patient experiences. This is an essential perspective, but much can be gained by exploring the roles of other actors, both individual and institutional, in shaping pain. How is the way we conceptualize and address pain shaped by the science, medicine, business, and politics of pain?

Even the most foundational facts about pain-including its definition and classification-are produced within social institutions. Whelan (2009), for instance, documents the sometimes tense international, interdisciplinary negotiations involved in creating the influential Classification of Chronic Pain. Future research, informed by sociology of science and of the professions, could unpack the professional "black boxes" in which pain-related norms and standards are created, and could assess which stakeholders' interests are prioritized in the process.

Institutional cultures may compete with each other, as when physicians and pharmacists face clashing medical versus legal frameworks in deciding who should be treated with opioids, or more broadly when medical, criminal-justice, public health, and pain advocates' imperatives collide (Chiarello, 2015, 2018; Thernstrom, 2010). More research is needed to understand how 
this wide range of actors and structures jointly shapes the experience of pain and pain management. Such research can also use pain as a case study to examine how institutions, professions, and social movements interact when they navigate a shared social space.

Politics and corporations are also critical players in pain. Commercial interests help shape ideas about pain and its treatment. The role of pharmaceutical marketing in the opioid epidemic is blatant, but corporate self-interest can have more subtle and nuanced effects. Barker (2011), for instance, describes how the approval and marketing of a new medication for fibromyalgia contributed to legitimation of the condition, but also created unrealistic expectations of patient function and recovery. Political discourse, pain-related policies, and regulations are also crucial: pain is deeply political, as it is central to debates and framing of suffering, morality, and social welfare in the context of health insurance or disability benefits (Wailoo, 2014). Interdisciplinary research should explore how politics and the corporate pursuit of profits (Montez, 2020) impact pain in the US and elsewhere. Such approaches can illuminate the core beliefs of a country's politics, culture, and society.

Finally, a global perspective in the form of international comparisons is powerful in making the influence of national cultures, norms, and policies visible and should be applied in research on pain and pain policy. For instance, despite roughly comparable chronic pain prevalence in Western Europe and the United States, opioid overdoses are seven times more common in the United States (Meyer, Leclair, \& Mcdonald, 2020). To what degree do legal and medical norms and regulations explain this difference? Overall, the rich institutional and sociopolitical landscape, at local, national, and international levels, is ripe for sociological examination.

\subsection{Foundational concepts in medical sociology and chronic pain}

Research on chronic pain could help advance foundational concepts in medical sociology-and vice versa. The life course perspective, for instance, has been successfully used to uncover important insights about health over the life span. This concept is mirrored by the "disease course" of chronic pain (Yang \& Grol-Prokopczyk, 2020), which considers how pain's duration, trajectory, and severity shape intra- and interpersonal outcomes. Many concepts from life course sociology, including "turning points," "critical periods," and "linked lives" could be fruitfully applied to pain research. For instance, the pivotal transition process from acute to chronic pain appears to be sensitive to social inputs; sociologists could clarify how social factors across the life course shape the risk of pain chronification.

Another foundational concept from the origin of medical sociology is the "sick role" (Parsons, 1951), which lays out social norms for patients and doctors. The invisibility of chronic pain and its sometimes-contested nature, however, undermine patient efforts at legitimation in ways unforeseen by Parsons. Moreover, pain physicians may also struggle to meet Parsonian ideals, such as of doctors as omnipotent authorities. Sociological studies could examine implications of such tensions (e.g., might doctors' prescription of opioids reflect a social pressure to "do 
something" for patients?), and more broadly could expand theories of patient and provider roles in unverifiable, difficult-to-treat conditions.

Other sociological concepts that may contribute fruitfully to pain-related research include hegemonic masculinity (or gender roles in general); the loss and reconstruction of self in chronic illness; and medicalization. A decade ago, a prominent scholar and critic of medicalization concluded that medicalization of pain, unlike for many other conditions, was beneficial, because it legitimized pain treatment and research (Conrad \& Muñoz, 2010). In the wake of the opioid epidemic, exposés of pharmaceutical companies' profiteering, and the new "chronic pain" classification in the ICD-11, a careful assessment of benefits versus harms of pain medicalization may be warranted. Overall, seminal sociological concepts, theories, and models could enrich studies of chronic pain, and could in turn be refined for today's health landscape by considering the unique and complex phenomenon of chronic pain.

\section{CONCLUSION}

Chronic pain is a sensitive barometer of health at the individual, population, and institutional levels. A rapidly evolving population-health scholarship on social aspects of chronic pain has recently generated important findings on pain prevalence, trends, and disparities. An important if modest body of sociological inquiry has examined pain's meanings, framings, and consequences to individuals as well as society. These contributions can serve as a foundation for deeper sociological study.

Among common, chronic physical health conditions, pain has a particularly strong association with psychological health problems. In part for this reason, pain may be particularly sensitive to the "health" of social welfare systems, health care systems, and Western medical paradigms. Because pain is a "biopsychosocial" and often intractable health problem, addressing it effectively depends on a social system that focuses on prevention and wellbeing, treats patients holistically, and can accommodate chronic, disabling health conditions. Presently, the US does none of these well. US healthcare currently focuses on reimbursement of individual procedures and quick pharmacological solutions rather than on integrative long-term approaches focused on patient self-management (Rubin et al., 2018).

In the late $19^{\text {th }}$ century, Durkheim launched empirical sociology by showing how a seemingly private act-suicide-reflected social forces, in particular the upheaval in the wake of the Industrial Revolution. In the $21^{\text {st }}$ century's post-industrial, neoliberal US, we may likewise gain important new insights into the impact of social forces, structures, policies, and contexts by examining an ostensibly private experience: pain. Overall, we hope to show that sociological approaches are poised to make important contributions to understanding chronic pain, and that pain, in turn, sheds light on many phenomena of interest to sociologists. The sociology of chronic pain is an important frontier for future sociological research. 


\section{REFERENCES}

Andersson, H.I. (2004). The course of non-malignant chronic pain: a 12-year follow-up of a cohort from the general population. European journal of pain, 8, 47-53.

Barker, K.K. (2005). The Fibromyalgia Story: Medical Authority and Women's Worlds of Pain. Philadelphia: Temple University Press.

Barker, K.K. (2011). Listening to Lyrica: contested illnesses and pharmaceutical determinism. Social Science and Medicine, 73, 833-842.

Basbaum, A.I., Bautista, D.M., Scherrer, G., \& Julius, D. (2009). Cellular and Molecular Mechanisms of Pain. Cell, 139, 267-284.

Baszanger, I. (1992). Deciphering chronic pain. Sociology of Health \& IIIness, 14, 181-215.

Bendelow, G. (1993). Pain perceptions, emotions and gender. Sociology of Health and IIIness, 15, 273-294.

Bendelow, G.A., \& Williams, S.J. (1995). Transcending the dualisms: towards a sociology of pain. Sociology of Health and IIIness, 17, 139-165.

Boddice, R. (2017). Pain: A Very Short Introduction: Oxford University Press.

Brennan, F., Carr, D.B., \& Cousins, M. (2007). Pain Management: A Fundamental Human Right. Anesthesiology, 107, 205-221.

Bury, M. (1982). Chronic illness as biographical disruption. Sociology of Health \& IIIness, 4, 167182.

Case, A., \& Deaton, A. (2020). The Misery and Mystery of Pain. Deaths of Despair and the Future of Capitalism pp. 83-93). Princeton NJ: Princeton University Press.

CDC. (2020). Opioid Overdose: Understanding the Epidemic.

Charmaz, K. (1983). Loss of self: a fundamental form of suffering in the chronically ill. Sociology of Health \& IIIness, 5, 168-195.

Chiarello, E. (2015). The War on Drugs Comes to the Pharmacy Counter: Frontline Work in the Shadow of Discrepant Institutional Logics. Law \& Social Inquiry, 40, 86-122.

Chiarello, E. (2018). Where movements matter: Examining unintended consequences of the pain management movement in medical, criminal justice, and public health fields. Law \& Policy, 40, 79-109.

Chou, R., Turner, J.A., Devine, E.B., Hansen, R.N., Sullivan, S.D., Blazina, I., et al. (2015). The Effectiveness and Risks of Long-Term Opioid Therapy for Chronic Pain: A Systematic Review for a National Institutes of Health Pathways to Prevention Workshop. Annals of Internal Medicine, 162, 276-286.

Clauw, D.J., Häuser, W., Cohen, S.P., \& Fitzcharles, M.-A. (2020). Considering the potential for an increase in chronic pain after the COVID-19 pandemic. Pain, 161, 1694-1697.

Cleveland, R.J., Nelson, A.E., \& Callahan, L.F. (2019). Knee and hip osteoarthritis as predictors of premature death: a review of the evidence. Clinical and experimental rheumatology, 37 Suppl 120, 24-30.

Conrad, P., \& Muñoz, V.L. (2010). The medicalization of chronic pain. The Journal for Research in Sickness and Society, 7, 13-24. 
Craig, K.D., \& Fashler, S.R. (2013). Social Determinants of Pain. In H. van Griensven, Strong, J., and Unruh, A.M. (Ed.), Pain: A Textbook for Therapists, Second Edition pp. 21-31): Elsevier.

Crossley, M. (1998). 'Sick Role' or 'Empowerment'? The Ambiguities of Life with an HIV Positive Diagnosis. Sociology of Health and IIIness, 20, 507-531.

Crowe, M., Whitehead, L., Seaton, P., Jordan, J., McCall, C., Maskill, V., et al. (2017). Qualitative meta-synthesis: the experience of chronic pain across conditions. Journal of Advanced Nursing, 73, 1004-1016.

Dahlhamer, J., Lucas, J., Zelaya, C., Nahin, R., Mackey, S., DeBar, L., et al. (2018). Prevalence of chronic pain and high-impact chronic pain among adults_United States, 2016. Morbidity and Mortality Weekly Report, 67, 1-6.

Davis, K.D., Aghaeepour, N., Ahn, A.H., Angst, M.S., Borsook, D., Brenton, A., et al. (2020). Discovery and validation of biomarkers to aid the development of safe and effective pain therapeutics: challenges and opportunities. Nature Reviews Neurology, 16, 381-400.

Dueñas, M., Ojeda, B., Salazar, A., Mico, J.A., \& Failde, I. (2016). A review of chronic pain impact on patients, their social environment and the health care system. Journal of Pain Research, 9, 457-467.

Eisenberger, N.I. (2015). Social Pain and the Brain: Controversies, Questions, and Where to Go from Here. Annual Review of Psychology, 66, 601-629.

Emch, T.M., \& Modic, M.T. (2011). Imaging of lumbar degenerative disk disease: history and current state. Skeletal Radiology, 40, 1175-1189.

Fujimura, J. (1996). Crafting Science: A Sociohistory of the Quest for the Genetics of Cancer. Cambridge, MA: Harvard University Press.

Galea, S., \& Vaughan, R.D. (2018). Causes and Causes of Causes of Population Health: A Public Health of Consequence, March 2018. American Journal of Public Health, 108, 304-305.

Gaskin, D.J., \& Richard, P. (2012). The economic costs of pain in the United States. The journal of pain : official journal of the American Pain Society, 13, 715-724.

Gatchel, R.J., Peng, Y.B., Peters, M.L., Fuchs, P.N., \& Turk, D.C. (2007). The biopsychosocial approach to chronic pain: Scientific advances and future directions. Psychological Bulletin, 133, 581-624.

Glenton, C. (2003). Chronic back pain sufferers--striving for the sick role. Social Science and Medicine, 57, 2243-2252.

Goosby, B.J. (2013). Early life course pathways of adult depression and chronic pain. Journal of Health and Social Behavior, 54, 75-91.

Graf, J. (2010). Analgesic use in the elderly: The "pain" and simple truth. Archives of Internal Medicine, 170, 1976-1978.

Green-Fulgham, S.M., Ball, J.B., Kwilasz, A.J., Fabisiak, T., Maier, S.F., Watkins, L.R., et al. (2019). Oxycodone, fentanyl, and morphine amplify established neuropathic pain in male rats. Pain, 160, 2634-2640. 
Greenwood, K.A., Thurston, R., Rumble, M., Waters, S.J., \& Keefe, F.J. (2003). Anger and persistent pain: current status and future directions. $P A I N \circledast, 103,1-5$.

Grol-Prokopczyk, H. (2013). Quantifying the Unquantifiable: The Measurement and Meanings of Chronic Pain. Ph.D. dissertation, Department of Sociology, University of WisconsinMadison, Madison, WI.

Grol-Prokopczyk, H. (2017). Sociodemographic disparities in chronic pain, based on 12-year longitudinal data. Pain, 158, 313-322.

Grol-Prokopczyk, H. (2019). Use and opinions of prescription opioids among older American adults: Sociodemographic predictors. Journal of Gerontology: Social Sciences, 74, 10091019.

Gureje, O., Von Korff, M., Kola, L., Demyttenaere, K., He, Y., Posada-Villa, J., et al. (2008). The relation between multiple pains and mental disorders: Results from the World Mental Health Surveys. Pain, 135, 82-91.

Hadi, M.A., Alldred, D.P., Briggs, M., Marczewski, K., \& Closs, S.J. (2017). 'Treated as a number, not treated as a person': A qualitative exploration of the perceived barriers to effective pain management of patients with chronic pain. BMJ Open, 7, e016454.

Hashmi, J.A., Baliki, M.N., Huang, L., Baria, A.T., Torbey, S., Hermann, K.M., et al. (2013). Shape shifting pain: chronification of back pain shifts brain representation from nociceptive to emotional circuits. Brain, 136, 2751-2768.

Hausmann, L.R.M., Gao, S., Lee, E.S., \& Kwoh, K.C. (2013). Racial disparities in the monitoring of patients on chronic opioid therapy. Pain, 154, 46-52.

Hoffman, K.M., Trawalter, S., Axt, J.R., \& Oliver, M.N. (2016). Racial bias in pain assessment and treatment recommendations, and false beliefs about biological differences between blacks and whites. Proceedings of the National Academy of Sciences of the United States of America, 113, 4296-4301.

Institute of Medicine. (2011). Relieving Pain in America: A Blueprint for Transforming Prevention, Care. The National Institutes of Health. Washington, DC.

Jackson, J.E. (2011). Pain: Pain and Bodies. In F.E. Mascia-Lees (Ed.), A Companion to the Anthropology of the Body and Embodiment pp. 370-387). West Sussex: Blackwell Publishing.

Janevic, M.R., McLaughlin, S.J., Heapy, A.A., Thacker, C., \& Piette, J.D. (2017). Racial and Socioeconomic Disparities in Disabling Chronic Pain: Findings From the Health and Retirement Study. The Journal of Pain, 18, 1459-1467.

Jay, M.A., Bendayan, R., Cooper, R., \& Muthuri, S.G. (2019). Lifetime socioeconomic circumstances and chronic pain in later adulthood: findings from a British birth cohort study. BMJ Open, 9, 1-10.

Joachim, G., \& Acorn, S. (2000). Stigma of visible and invisible chronic conditions. Journal of Advanced Nursing, 32, 243-248.

Johannes, C.B., Le, T.K., Zhou, X., Johnston, J.A., \& Dworkin, R.H. (2010). The Prevalence of Chronic Pain in United States Adults: Results of an Internet-Based Survey. The Journal of Pain, 11, 1230-1239. 
Jones, M.R., Viswanath, O., Peck, J., Kaye, A.D., Gill, J.S., \& Simopoulos, T.T. (2018). A Brief History of the Opioid Epidemic and Strategies for Pain Medicine. Pain and Therapy, 7, 13-21.

Karos, K., Williams, A.C.d.C., Meulders, A., \& Vlaeyen, J.W.S. (2018). Pain as a threat to the social self: a motivational account. Pain, 159, 1690-1695.

Kempner, J. (2014). Not tonight: Migraine and the politics of gender and health: University of Chicago Press.

Kempner, J. (2016). What Biology Can't Do. Headache, 56, 1047-1052.

Kennedy, J., Roll, J.M., Schraudner, T., Murphy, S., \& McPherson, S. (2014). Prevalence of Persistent Pain in the U.S. Adult Population: New Data From the 2010 National Health Interview Survey. The Journal of Pain, 15, 979-984.

Macfarlane, G.J., Barnish, M.S., \& Jones, G.T. (2017). Persons with chronic widespread pain experience excess mortality: longitudinal results from UK Biobank and meta-analysis. Annals of the Rheumatic Diseases, 76, 1815-1822.

Matthias, M.S., Parpart, A.L., Nyland, K.A., Huffman, M.A., Stubbs, D.L., Sargent, C., et al. (2010). The Patient-Provider Relationship in Chronic Pain Care: Providers' Perspectives. Pain Medicine, 11, 1688.

Melzack, R. (1999). From the gate to the neuromatrix. Pain, 82, S121-S126.

Melzack, R., \& Wall, P.D. (1965). Pain Mechanisms: A New Theory. Science, 150, 971.

Meyer, A., Leclair, C., \& Mcdonald, J.V. (2020). Prescription opioid Prescribing in western Europe and the united states. Rhode Island Medical Journal, 103, 45-48.

Mills, C.W. (1959). The Promise. The Sociological Imagination pp. 1-6): Oxford University Press.

Moayedi, M., \& Davis, K.D. (2013). Theories of pain: from specificity to gate control. Journal of neurophysiology, 109, 5-12.

Montez, J.K. (2020). US State Polarization, Policymaking Power, and Population Health. The Milbank Quarterly, 98, 1033-1052.

Moriarty, O., McGuire, B.E., \& Finn, D.P. (2011). The effect of pain on cognitive function: A review of clinical and preclinical research. Progress in Neurobiology, 93, 385-404.

Nahin, R.L. (2015). Estimates of Pain Prevalence and Severity in Adults: United States, 2012. The Journal of Pain, 16, 769-780.

O'Leary, D. (2018). Why Bioethics Should Be Concerned With Medically Unexplained Symptoms. The American Journal of Bioethics, 18, 6-15.

Parsons, T. (1951). Social Structure and Dynamic Process: The Case of Modern Medical Practice. The Social System pp. 418-479). London: The Free Press.

Patel, K.V., Guralnik, J.M., Dansie, E.J., \& Turk, D.C. (2013). Prevalence and impact of pain among older adults in the United States: Findings from the 2011 National Health and Aging Trends Study. PAIN®, 154, 2649-2657.

Phelan, J.C., Link, B.G., \& Tehranifar, P. (2010). Social conditions as fundamental causes of health inequalities: theory, evidence, and policy implications. Journal of Health and Social Behavior, 51 Suppl, S28-40. 
Pryma, J. (2017). "Even my sister says I'm acting like a crazy to get a check": Race, gender, and moral boundary-work in women's claims of disabling chronic pain. Social Science \& Medicine, 181, 66-73.

Racine, M. (2018). Chronic pain and suicide risk: A comprehensive review. Progress in NeuroPsychopharmacology and Biological Psychiatry, 87, 269-280.

Raffaeli, W., \& Arnaudo, E. (2017). Pain as a disease: an overview. Journal of Pain Research, 10, 2003-2008.

Raja, S.N., Carr, D.B., Cohen, M., Finnerup, N.B., Flor, H., Gibson, S., et al. (2020). The revised International Association for the Study of Pain definition of pain: concepts, challenges, and compromises. Pain, Articles in Press.

Reckziegel, D., Vachon-Presseau, E., Petre, B., Schnitzer, T.J., Baliki, M.N., \& Apkarian, A.V. (2019). Deconstructing biomarkers for chronic pain context- and hypothesis-dependent biomarker types in relation to chronic pain. Pain, 160, S37-S48.

Rice, A.S.C., Smith, B.H., \& Blyth, F.M. (2016). Pain and the global burden of disease. Pain, 157, 791-796.

Rouse, C. (2009). Uncertain Suffering: Racial Health Care Disparities and Sickle Cell Disease: University of California Press.

Rubin, S., Burke, N., Van Natta, M., Yen, I., \& Shim, J.K. (2018). Like a Fish out of Water: Managing Chronic Pain in the Urban Safety Net. Journal of Health and Social Behavior, $59,487-500$.

Rubin, S., \& Zimmer, Z. (2015). Pain and self-assessed health: Does the association vary by age? Social Science \& Medicine, 130, 259-267.

Samulowitz, A., Gremyr, I., Eriksson, E., \& Hensing, G. (2018). "Brave Men" and "Emotional Women": A Theory-Guided Literature Review on Gender Bias in Health Care and Gendered Norms towards Patients with Chronic Pain. Pain Research and Management, 2018, 1-14.

Scarry, E. (1985). The Body in Pain. New York: Oxford University Press.

Siddall, P. (2013). Is Chronic Pain a Disease? Pain Medicine, 14, 1289-1290.

Smith, B.H., Elliott, A.M., Hannaford, P.C., Chambers, W.A., \& Smith, W.C. (2004). Factors Related to the Onset and Persistence of Chronic Back Pain in the Community: Results From a General Population Follow-up Study. Spine, 29, 1032-1040.

Smith, D., Wilkie, R., Croft, P., Parmar, S., \& McBeth, J. (2018). Pain and Mortality: Mechanisms for a Relationship. Pain, 159, 1112-1118.

Smith, D., Wilkie, R., Uthman, O., Jordan, J.L., \& McBeth, J. (2014). Chronic pain and mortality: a systematic review. PLoS One, 9, e99048.

Smith, J.A., \& Osborn, M. (2007). Pain as an assault on the self: An interpretative phenomenological analysis of the psychological impact of chronic benign low back pain. Psychology \& Health, 22, 517-534.

Social Security Administration. (2017). Code Of Federal Regulations (§ 404.1529. How we evaluate symptoms, including pain). Washington, DC. 
Stokes, A.C., Xie, W., Lundberg, D.J., Hempstead, K., Zajacova, A., Zimmer, Z., et al. (2020). Increases in BMI and Chronic Pain for US Adults in Midlife, 1992 to 2016. SSMPopulation Health, 12, 1-8.

Strunin, L., \& Boden, L.I. (2004). Family consequences of chronic back pain. Social Science \& Medicine, 58, 1385-1393.

Thernstrom, M. (2010). The Pain Chronicles: Cures, Myths, Mysteries, Prayers, Diaries, Brain Scans, Healing, and the Science of Suffering. New York: Farrar, Strauss and Giroux.

Turk, D.C., Fillingim, R.B., Ohrbach, R., \& Patel, K.V. (2016). Assessment of Psychosocial and Functional Impact of Chronic Pain. The Journal of Pain, 17, T21-T49.

Turk, D.C., Wilson, H., Swanson, K.S., Ebert, M., \& Kerns, R. (2011a). The biopsychosocial model of pain and pain management: Cambridge University Press Cambridge.

Turk, D.C., Wilson, H.D., \& Cahana, A. (2011b). Treatment of chronic non-cancer pain. Lancet, 377, 2226-2235.

Upshur, C.C., Bacigalupe, G., \& Luckmann, R. (2010). "They don't want anything to do with you": patient views of primary care management of chronic pain. Pain Medicine, 11, 1791-1798.

Verbrugge, L.M., \& Jette, A.M. (1994). The Disablement Process. Social Science and Medicine, 38, 1-14.

Viana, M.C., Lim, C.C.W., Garcia Pereira, F., Aguilar-Gaxiola, S., Alonso, J., Bruffaerts, R., et al. (2018). Previous Mental Disorders and Subsequent Onset of Chronic Back or Neck Pain: Findings From 19 Countries. The Journal of Pain, 19, 99-110.

Volkow, N.D., \& McLellan, A.T. (2016). Opioid Abuse in Chronic Pain - Misconceptions and Mitigation Strategies. New England Journal of Medicine, 374, 1253-1263.

Wailoo, K. (2014). Pain: A Political History: Johns Hopkins University Press.

Whelan, E. (2009). How classification works, or doesn't: The case of chronic pain. In D. Byrne, \& C. Ragin (Eds.), The SAGE Handbook of Case-Based Methods pp. 169-182). London: SAGE.

WHO. (2019). International Statistical Classification of Diseases and Related Health Problems (11th ed.).

Woolf, C.J. (2004). Pain: Moving from Symptom Control toward Mechanism-Specific Pharmacologic Management. Annals of Internal Medicine, 140, 441-451.

World Health Organization. (2013). How to use the ICF: A Practical Manual for using the International Classification of Functioning, Disability and Health (ICF). Geneva: World Health Organization.

Yang, Y., \& Grol-Prokopczyk, H. (2020). Chronic Pain and Friendship among Middle-Aged and Older U.S. Adults. Journal of Gerontology: Series B Social Sciences, Published 29 October 2020.

Zajacova, A., Rogers, R.G., Grodsky, E., \& Grol-Prokopczyk, H. (2020). The Relationship between Education and Pain among Adults Aged 30-49 in the United States. Journal of Pain 21, 1270-1280. 
Zajacova, A., Zimmer, Z., \& Grol-Prokopczyk, H. (2021). Pain trends among American adults 2002-2018: Patterns, disparities, and correlates. Demography, Forthcoming.

Zimmer, Z., \& Rubin, S. (2020). Pain and Disablement. Health Expectancies.

Zimmer, Z., \& Zajacova, A. (2020). Persistent, Consistent and Extensive: The Trend of Increasing Pain Prevalence in Older Americans. Journals of Gerontology: Social Sciences, 75, 436-447.

Zimmer, Z., Zajacova, A., \& Grol-Prokopczyk, H. (2020). Trends in Pain Prevalence among Adults 50 and Older across Europe, 2004 to 2015. Journal of Aging and Health, 32, 1419-1432.

Zola, I.K. (1966). Culture and symptoms--an analysis of patient's presenting complaints. American Sociological Review, 615-630. 
Figure 1. Predicted probability of severe pain in US adults 30-84.

$\frac{1}{0}$
$\frac{一}{0}$
0
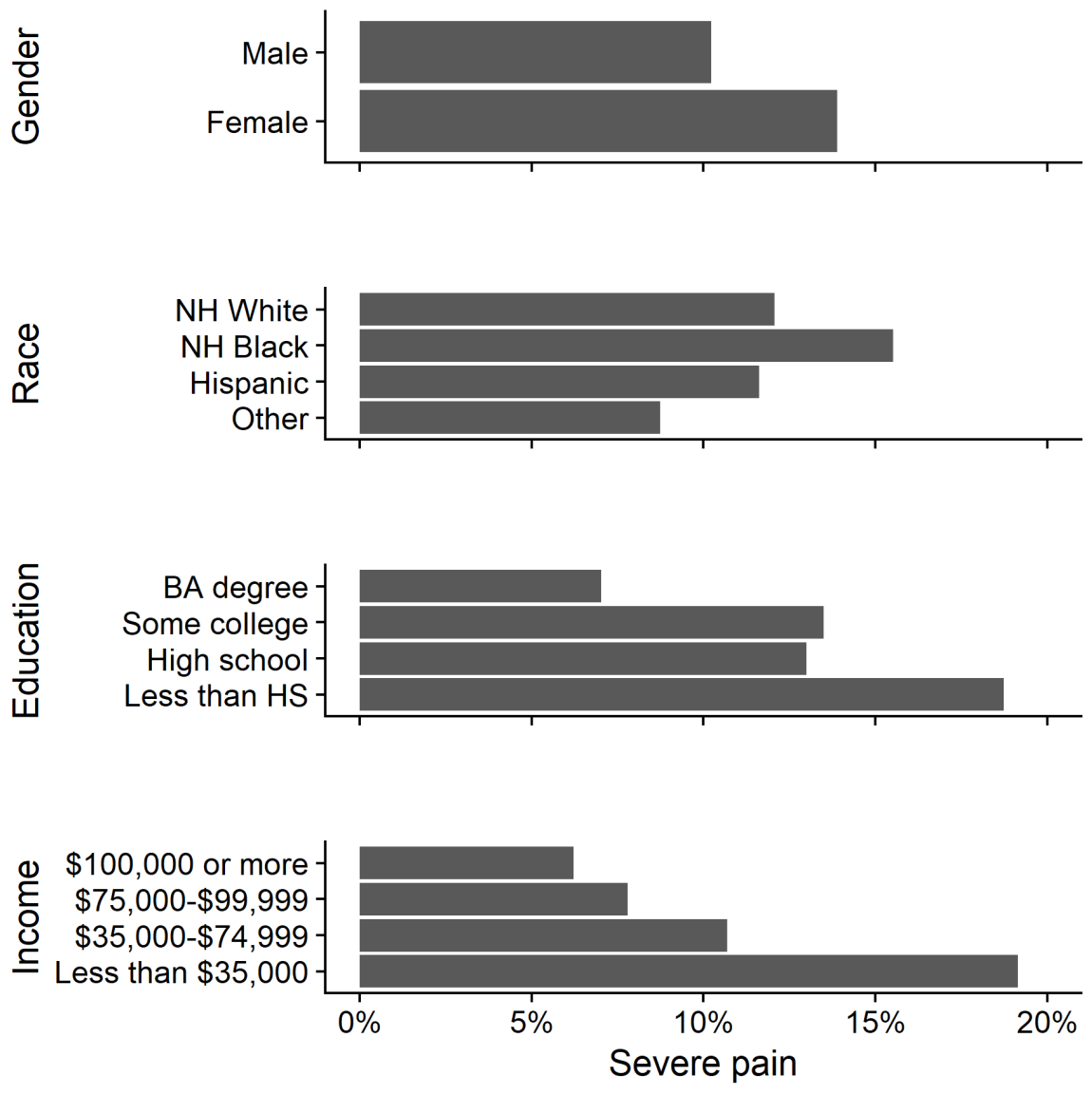

See Online Appendix describes for detail. Source: NHIS 2010-2018. 
Figure 2. Correlations between pain severity and other health measures, US adults 30-84.

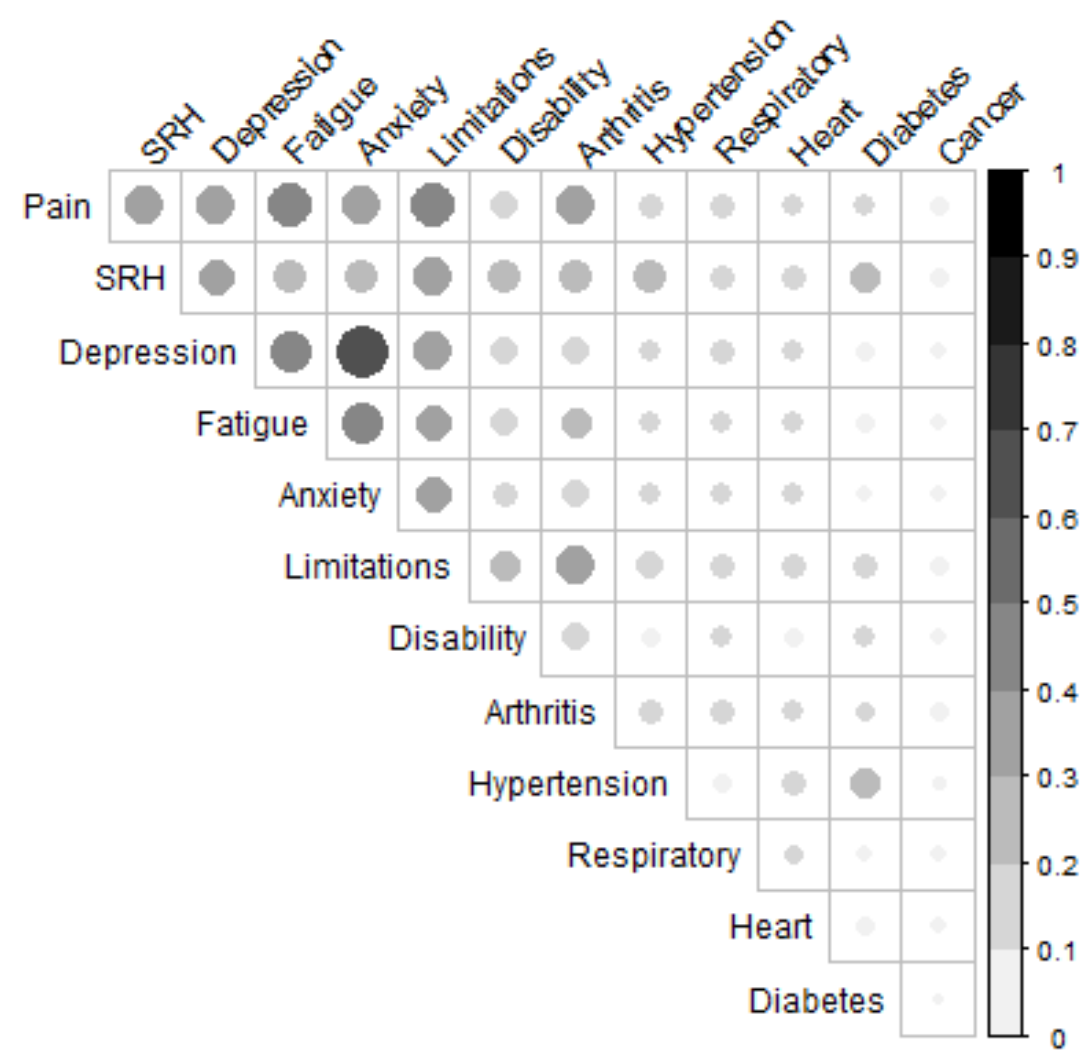

See Online Appendix for detail. SRH=self-rated health. Source: NHIS 2010-2018. 
Figure 3. Predicted probability of survival by pain severity, US adults aged 30-84.

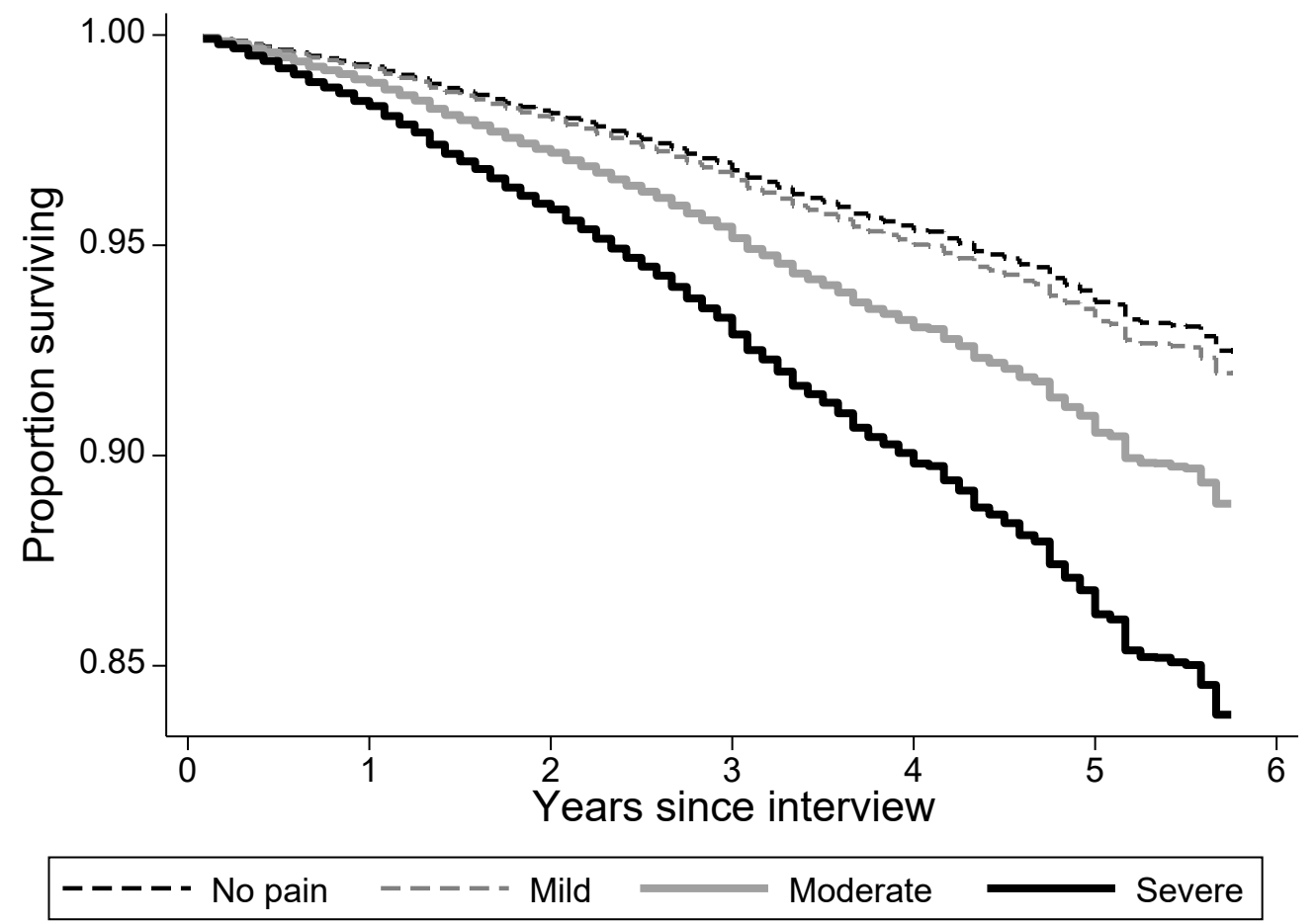

See Online Appendix for detail. Source: NHIS 2010-2014 linked to mortality followup through 2015. 


\section{ONLINE APPENDIX}

This document describes the data and approach we used to generate Figures 1-3 in the Sociology of Chronic Pain manuscript.

\section{Data}

We used data from the 2010-2018 National Health Interview Survey (Blewett et al., 2019), a large annual cross-sectional survey that is nationally representative of the noninstitutionalized US population. The NHIS includes detailed about pain intensity and all necessary covariates. 2010 was the first year used because the pain questions we use here were not asked earlier. 2018 is the last year used because that's the most recent wave available at the time of the analysis.

We included respondents aged 30 to 84 who were administered the detailed pain questions. In 2010 the pain questions were asked as a part of the Quality of Life supplement of a random subsample of respondents. In 2011-2017, the detailed pain questions were collected for a subset administered the Adult Functioning and Disability Supplement; and in 2018, the questions were posed to all 'sample adults.' Sampling weight are used to account for differential probability of selection into these subsamples: supplement weight (supp1wt) for 2010-2017 and sample adult weight (sampweight) for 2018, following NCHS guidelines (https://nhis.ipums.org/nhis-action/variables/PAINFREQ3MO\#weights section). Variance adjustment for logistic regression models and Cox proportional hazard models was based on Taylor series linear approximation. All analyses were estimated in Stata 16.1 (StataCorp, 2021). The data are publicly-available and fully de-identified; as such, no Institutional Board Approval was required.

We selected 30 as the lower threshold for age because over $13 \%$ of US adults younger than 30 are still enrolled in postsecondary schooling and thus do not have a completed education or established occupation and thus income, as compared to less than 7\% at ages 30-34 (National Center for Education Statistics, 2017). The upper age threshold of 84 was selected because older ages were top-coded at 85 in the NHIS data. We also included only respondents with valid pain intensity information. This sample definition included 98,202 respondents. Age, sex, and race had no missing values; education was missing for 354 respondents $(<0.36 \%)$ and family income was missing for 6,667 respondents (6.8\%). The sample sizes differ across analyses, as we describe below specifically for each Figure.

\section{Variables}

Pain. The pain measure was collected using a screener frequency question and followup severity question. Pain frequency assessed whether, and how frequently, respondents had pain in the past 3 months (painfreq3mo). Respondents were asked: "In the past 3 months, how often did you have pain? Would you say never, some days, most days, or every day?" Pain severity assessed the level of pain. Respondents who indicated that they had pain at least "some days during the past 3 months" were asked: "Thinking about the last time you had pain, how much 
pain did you have? Would you say a little, a lot, or somewhere in between?" We combine this information into a 4-level pain variable: respondents who said they "never" experienced pain were coded as "no pain," those who did are then coded using the second question as "mild," "moderate," and "severe" pain.

Covariates. Age was collected in single years and is included in the models as a continuous linear term. Gender is included with male as reference. Race is created from questions about Hispanic ethnicity and self-reported race and coded as non-Hispanic White, non-Hispanic Black, Hispanic, and Other. Education is assessed in terms of highest completed level and coded as less than high school, high school diploma, some higher education (including subbaccalaureate credentials), and bachelor's degree or more. Finally, family income is coded in the NHIS as $\$ 0$ $\$ 34,999, \$ 35,000-\$ 74,999, \$ 75,000-\$ 99,999$, and $\$ 100,000$ or above.

Health variables for the correlation matrix in Figure 2 are measured and coded as follows:

- Self-rated health was assessed with the standard question "In general, would you say your health is excellent, very good, good, fair, or poor?"

- Depressive symptoms were measured using the Kessler Scale (K6), which captures manifestations of six dimensions of psychological distress during the past month. This scale, widely-used to measure population mental health (Kessler et al., 2002; Prochaska et al., 2012), has a 0-24 range; higher scores indicate more severe symptoms.

- For depressive symptoms, respondents were asked: "How often do you feel depressed? Would you say daily $(=5)$, weekly, monthly, a few times a year, or never $(=1)$ ?"

- Fatigue was assessed as "In the past 3 months, how often did you feel very tired or exhausted? Would you say never $(=1)$, some days, most days, or every day $(=4) ? "$

- Anxiety was assessed in the following way: "How often do you feel worried, nervous or anxious? Would you say daily (=4), weekly, monthly, a few times a year, or never (=1)?"

- Functional limitations is a dichotomous indicator coded 1 if any and 0 if no limitations, and was created in NHIS from 12 individual questions about difficulties with various activities like walking 3 city blocks, walking up 10 steps, grasping small objects, or participating in social activities.

- Disability is a dichotomous indicator coded 1 if a respondent has activity limitation, including difficulty needing help with activities of daily living such as eating, bathing, or dressing, or instrumental activities if daily living such as chores or errands.

- Physical chronic conditions were assessed using the yes/no prompt: "Have you ever been told by a doctor or other health professional that you had ...?" The conditions include arthritis, cancer, diabetes, hypertension, stroke, respiratory (chronic bronchitis or emphysema), and heart (angina pectoris, CHD, heart attack, and other heart conditions).

\section{Figure 1. Predicted probabilities of severe pain for select groups.}

Figure 1 in the manuscript shows predicted probability of severe pain (the pain level most predictive of disability and mortality) by gender, race/ethnicity, education, and income. 
We estimated logistic regression models of severe pain (vs. none, mild, or moderate pain) adjusted for complex survey design of the data source, as a function of the following covariates:

- Age and gender for gender-stratified results

- Age, gender, and race for race-stratified results

- Age, gender, race, and education for education-stratified results

- Age, gender, race, and income for income-stratified results.

We then calculated the average predicted probability of severe pain for each category of the target variables -- gender, race, education, and income, respectively. This calculation yielded the probability of severe pain we would observe if everyone in the sample had a given level of the covariate (say, family income for the last graph) but otherwise would retain their actual values on all covariates. The findings were visually indistinguishable when we calculated the predicted probabilities at mean levels of all covariates.

All models adjusted for the complex survey design using the svy suite of commands. We used supplement weight (supp1wt) for 2010-2017 and sample adult weight (sampweight) for 2018 as appropriate for the sampling structure across the available years (https://nhis.ipums.org/nhisaction/variables/PAINFREQ3MO\#weights section).

Appendix Table 1 shows the results from the logistic models from which the predicted probabilities were calculated.

\begin{tabular}{|c|c|c|c|c|c|c|}
\hline \multicolumn{7}{|c|}{ Appendix Table 1. Logistic regression models of severe pain } \\
\hline & \multicolumn{2}{|c|}{ Model 1} & \multicolumn{2}{|c|}{ Model 2} & \multicolumn{2}{|c|}{ Model 3} \\
\hline Age & $1.01^{* * *}$ & $1.01,1.01$ & $1.00^{* * *}$ & $1.00,1.01$ & $1.00^{* *}$ & $1.00,1.00$ \\
\hline Female & $1.40^{* * *}$ & $1.33,1.48$ & $1.40^{* * *}$ & $1.32,1.48$ & $1.32^{* * *}$ & $1.24,1.39$ \\
\hline Race (NH White) & 1.00 & $1.00,1.00$ & 1.00 & $1.00,1.00$ & 1.00 & $1.00,1.00$ \\
\hline NH Black & $1.37^{* * *}$ & $1.27,1.48$ & $1.19^{* \star *}$ & $1.10,1.28$ & 1.05 & $0.97,1.13$ \\
\hline Hispanic & 1.02 & $0.93,1.10$ & $0.74^{* * *}$ & $0.68,0.81$ & $0.77^{* * *}$ & $0.70,0.84$ \\
\hline Other & $0.68^{* * *}$ & $0.60,0.77$ & $0.72^{* * *}$ & $0.63,0.81$ & $0.66^{* * *}$ & $0.58,0.75$ \\
\hline \multicolumn{7}{|l|}{ Education (BA+) } \\
\hline Less than $\mathrm{HS}$ & & & $3.36^{* * *}$ & $3.08,3.67$ & & \\
\hline High school & & & $1.94^{* * *}$ & $1.78,2.11$ & & \\
\hline Some college & & & $2.07^{\star \star \star}$ & $1.92,2.24$ & & \\
\hline Family income & & & & & $3.47^{* * *}$ & $3.18,3.79$ \\
\hline \multicolumn{7}{|l|}{$(>\$ 100,000)$} \\
\hline$\$ 0-\$ 34,999$ & & & & & $1.80^{* * *}$ & $1.64,1.98$ \\
\hline$\$ 35,000-\$ 74,999$ & & & & & $1.33^{* * *}$ & $1.18,1.50$ \\
\hline$\$ 75,000-\$ 99,999$ & & & & & 1.00 & $1.00,1.00$ \\
\hline
\end{tabular}

${ }^{*} p<.05,{ }^{* *} p<.01,{ }^{* * *} p<.001$

Odds ratios and their $95 \%$ confidence intervals shown.

Complete-case analysis; $\mathrm{N}=98,202$ in Model 1; $\mathrm{N}=97,848$ in Model 2; $\mathrm{N}=91,417$ in Model 3. All models take into account the complex sampling design of the NHIS. Source: NHIS 2010-2018. 


\section{Figure 2. Correlation matrix for pain and other health variables.}

Figure 2 in the manuscript shows a correlation matrix between pain and a host of other health measures.

We calculated a correlation matrix between pain (coded as $1=$ no pain, 2=mild, $3=$ =moderate, and $4=$ 'a lot of' pain and other health indicators. All other measures are specified as explained above and in every case higher values indicate worse health so that all correlations are positive.

We used NHIS data form 2010-2018. We calculated Pearson correlation, Spearman's rankorder correlation, and polychoric correlation for ordinal variables. Weighted and unweighted estimates differed immaterially.

Table $2 a$ and $2 b$ below show results from polychoric and Pearson correlations. The tables differ somewhat the overall portrait shows pain intensity to be correlated with especially strongly with fatigue, functional limitations, arthritis, depression, anxiety, and self-rated health, as well as with all other indicators.

\begin{tabular}{|c|c|c|c|c|c|c|c|c|c|c|c|c|c|}
\hline 1. Pain & 1 & 2 & 3 & 4 & 5 & 6 & 7 & 8 & 9 & 10 & 11 & 12 & 13 \\
\hline 2. Depression & 0.43 & & & & & & & & & & & & \\
\hline 3. Anxiety & 0.41 & 0.75 & & & & & & & & & & & \\
\hline 4. Fatigue & 0.52 & 0.50 & 0.51 & & & & & & & & & & \\
\hline 5. SRH & 0.38 & 0.36 & 0.27 & 0.30 & & & & & & & & & \\
\hline 6. Disability & 0.51 & 0.48 & 0.41 & 0.42 & 0.65 & & & & & & & & \\
\hline 7. Func. limitations & 0.61 & 0.47 & 0.42 & 0.45 & 0.52 & 0.72 & & & & & & & \\
\hline 8. Arthritis & 0.52 & 0.31 & 0.27 & 0.35 & 0.39 & 0.48 & 0.59 & & & & & & \\
\hline 9. Cancer & 0.21 & 0.18 & 0.18 & 0.18 & 0.23 & 0.26 & 0.27 & 0.24 & & & & & \\
\hline 10. Diabetes & 0.21 & 0.18 & 0.13 & 0.19 & 0.44 & 0.37 & 0.34 & 0.25 & 0.14 & & & & \\
\hline 11. Heart & 0.27 & 0.23 & 0.23 & 0.24 & 0.32 & 0.34 & 0.36 & 0.32 & 0.22 & 0.27 & & & \\
\hline 12. Hypertension & 0.24 & 0.19 & 0.17 & 0.20 & 0.39 & 0.33 & 0.32 & 0.31 & 0.13 & 0.47 & 0.35 & & \\
\hline 13. Respiratory & 0.33 & 0.30 & 0.27 & 0.30 & 0.35 & 0.41 & 0.40 & 0.37 & 0.21 & 0.24 & 0.33 & 0.25 & \\
\hline 14. Stroke & 0.30 & 0.23 & 0.19 & 0.21 & 0.39 & 0.47 & 0.38 & 0.28 & 0.28 & 0.32 & 0.43 & 0.39 & 0.33 \\
\hline
\end{tabular}




\begin{tabular}{|c|c|c|c|c|c|c|c|c|c|c|c|c|c|}
\hline & 1 & 2 & 3 & 4 & 5 & 6 & 7 & 8 & 9 & 10 & 11 & 12 & 13 \\
\hline 2. Depression & 0.32 & & & & & & & & & & & & \\
\hline 3. Anxiety & 0.31 & 0.65 & & & & & & & & & & & \\
\hline 4. Fatigue & 0.43 & 0.40 & 0.41 & & & & & & & & & & \\
\hline 5. SRH & 0.37 & 0.31 & 0.23 & 0.31 & & & & & & & & & \\
\hline 6. Disability & 0.22 & 0.21 & 0.15 & 0.19 & 0.32 & & & & & & & & \\
\hline 7. Func. lims. & 0.46 & 0.28 & 0.24 & 0.29 & 0.44 & 0.26 & & & & & & & \\
\hline 8. Arthritis & 0.37 & 0.17 & 0.13 & 0.19 & 0.29 & 0.18 & 0.43 & & & & & & \\
\hline 9. Cancer & 0.09 & 0.04 & 0.02 & 0.04 & 0.11 & 0.07 & 0.15 & 0.15 & & & & & \\
\hline 10. Diabetes & 0.14 & 0.08 & 0.04 & 0.09 & 0.29 & 0.14 & 0.22 & 0.17 & 0.07 & & & & \\
\hline 11. Heart & 0.17 & 0.10 & 0.07 & 0.12 & 0.26 & 0.16 & 0.24 & 0.21 & 0.13 & 0.18 & & & \\
\hline 12. Hypertension & 0.19 & 0.09 & 0.05 & 0.09 & 0.31 & 0.14 & 0.29 & 0.27 & 0.12 & 0.29 & 0.25 & & \\
\hline 13. Respiratory & 0.16 & 0.14 & 0.11 & 0.15 & 0.21 & 0.14 & 0.18 & 0.15 & 0.07 & 0.08 & 0.14 & 0.11 & \\
\hline 14. Stroke & 0.10 & 0.08 & 0.05 & 0.07 & 0.17 & 0.18 & 0.15 & 0.10 & 0.06 & 0.12 & 0.18 & 0.15 & 0.09 \\
\hline
\end{tabular}

\section{Figure 3. Survival curves.}

The NHIS included mortality followup for individuals interviewed up to the 2014 wave. The survival analysis is thus based on respondents interviewed in 2010-2014, years that overlap the availability of the pain severity question and mortality followup information, and who answered the pain severity question. From this group of 50,439 individuals, $874(1.7 \%)$ had ineligible mortality followup information (as determined by the National Center for Health Statistics, typically because they did not provide sufficient identifying information during the NHIS interview); we also excluded 2 individuals who were actually interviewed in January 2015, that is, outside the defined range, so the sample size for the survival models is $N=49,563$.

The followup mortality information was determined by the National Center for Health Statistics, based on probabilistic matches of the participants' NHIS records to the National Death Index (NDI) records (https://www.cdc.gov/nchs/data-

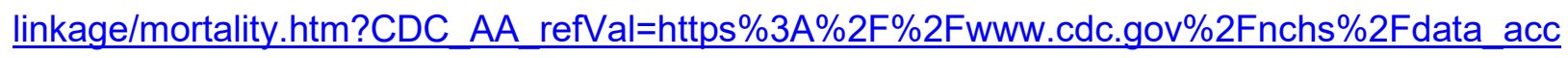
ess\%2Fdata linkage\%2Fmortality.htm). As of January 15, 2021 when this analysis was last updated, the linked mortality file included followup through December 31, 2015. The duration of followup in our analysis was o to 6 years, with average followup of 2.95 years. During this time, 
$1,594(3.22 \%)$ died; their average followup time was 2.06 years as compared to the followup time of 2.98 years for survivors.

We estimated Cox proportional survival models controlling for age and sex. The model accounted for the complex sampling design of the NHIS; the proportionality assumption was checked using the log-log plot since the Schoenfeld residuals are not calculated when models adjust for complex sampling design. The log-log plot suggested no obvious violation of the proportional hazards assumption. The Figure 3 in the manuscript graphs the predicted survival for the 4 pain severity groups at age 65 and balanced evenly between men's and women's survival curves.

The Appendix Table 2 below shows the estimated hazard ratios from Cox proportional-hazard models adjusted for different covariate groups.

Appendix Table 3. Mortality hazard by pain levels.

\begin{tabular}{lllllll}
\hline & \multicolumn{2}{c}{ Model 1 } & \multicolumn{2}{c}{ Model 2 } & \multicolumn{2}{c}{ Model 3 } \\
Pain (ref = no pain) & & & & & & \\
$\quad$ Mild pain & 1.08 & $0.91,1.28$ & 1.09 & $0.91,1.30$ & 1.04 & $0.86,1.26$ \\
Moderate pain & $1.52^{* * *}$ & $1.26,1.82$ & $1.53^{* * *}$ & $1.28,1.84$ & $1.31^{* *}$ & $1.08,1.60$ \\
Severe pain & $2.27^{* * *}$ & $1.89,2.73$ & $2.18^{* * *}$ & $1.82,2.62$ & $1.65^{* * *}$ & $1.34,2.03$ \\
& & & & & & \\
Age & $1.07^{* * *}$ & $1.07,1.08$ & $1.07^{* * *}$ & $1.07,1.08$ & $1.06^{* * *}$ & $1.05,1.07$ \\
Female & $0.64^{* * *}$ & $0.57,0.73$ & $0.59^{* * *}$ & $0.52,0.66$ & $0.56^{* * *}$ & $0.49,0.64$ \\
\hline${ }^{*} \mathrm{p}<.05,{ }^{* *} p<.01,{ }^{* * *} \mathrm{p}<.001$ & & & & &
\end{tabular}

Mortality hazard ratios and their $95 \%$ confidence intervals shown for key covariates from Cox proportional hazard models.

Model 2 also controls for important additional demographic characteristics: race, language of interview not English, immigrant status, region of residence, marital status, and having any children at home. Model $\mathbf{3}$ controls for all these characteristics plus socioeconomic factors: educational attainment, employment status, family income, and home ownership.

Complete-case analysis; $\mathrm{N}=49,563$ in Model 1; $\mathrm{N}=49,339$ in Model 2; $\mathrm{N}=46,275$ in Model 3. All models take into account the complex sampling design of the NHIS. Source data: NHIS 20102014 linked to the National Death Index through December 31, 2015. 


\section{REFERENCES}

Surveys: National Health Interview Survey, Version 6.4 [dataset]." edited by IPUMS. Minneapolis, MN.

Kessler, R.C., G. Andrews, L.J. Colpe, and E. al. 2002. "Short screening scales to monitor population prevalences and trends in non-specific psychological distress." Psychological Medicine 32(06):959-976.

National Center for Education Statistics. 2017. "Share of adult population enrolled in college or other higher education in the United States from 1970-2015, by age group."

Prochaska, J.J., H.-Y. Sung, W. Max, Y. Shi, and M. Ong. 2012. "Validity study of the K6 scale as a measure of moderate mental distress based on mental health treatment need and utilization." International Journal of Methods in Psychiatric Research 21(2):88-97.

StataCorp. 2021. "Stata Statistical Software: Release 16.1." College Station, TX: StataCorp LLC. 